\title{
Evaluación de parámetros productivos y reproductivos en un hato de doble propósito en Tabasco, México
}

\section{Productive and reproductive parameters in dual-purpose Zebu x Holstein cattle in Tabasco, Mexico}

\author{
Carlos Arce Recinosa , Emilio Manuel Aranda Ibáñez*, Mario Manuel Osorio Arcea, Roberto González \\ Garduñob ${ }^{b}$ Pablo Díaz Riverac, J osé Alfonso Hinojosa Cuellard
}

\begin{abstract}
RESUMEN
El objetivo del estudio fue evaluar el comportamiento productivo y reproductivo de bovinos Bos taurus (BT) x Bos indicus (BI) en un sistema de doble propósito, bajo las condiciones tropicales del estado de Tabasco. Los registros se obtuvieron de la unidad de producción, UACH-URUSSE, ubicada en Teapa, Tabasco. Los años evaluados fueron 1994 a 2011 , presentando información de 492 partos, y 240 lactancias completas de 130 vacas Cebú o sus cruzas (BT x BI). Los genotipos presentes en este estudio fueron las cruzas de Cebú (C) x Holstein (H): ${ }^{7 /} /{ }_{8} \mathrm{C}^{1} /{ }_{8} \mathrm{H},{ }_{3} /{ }_{4} \mathrm{C}^{1} /{ }_{4} \mathrm{H}, 5 /{ }_{8} \mathrm{C}^{3} /{ }_{8} \mathrm{H}, 1 /{ }_{2} \mathrm{C}^{1} /{ }_{2} \mathrm{H}, 5 /{ }_{8} \mathrm{~h}^{3} /{ }_{8} \mathrm{C}, 11 /{ }_{16} \mathrm{H}^{5} /{ }_{16} \mathrm{C}^{3} /{ }_{4} \mathrm{H}^{1} /{ }_{4} \mathrm{C}$; estos se agruparon en tres categorías $0-25 \%$, 37.5-50\% y $62.5-75 \%$ de acuerdo a la proporción de genes $\mathrm{BT}$. Las variables incluyeron peso al nacimiento (PN), intervalo entre partos (IEP), producción de leche por lactancia (PLL) y duración de lactancia (DL). Los resultados indicaron que los genotipos con mayor proporción de genes BT influyó favorablemente sobre PLL $(P<0.05)$ y $D L(P<0.01)$, mientras que no afectó PN e IEP $(P>0.05)$. El genotipo $62.5-75 \%$ presentó la mejor PLL $(1,262.80 \pm 34.80 \mathrm{~kg})$ y la DL más prolongada $(260.34 \pm$ 11.20 días); comparada con los genotipos 0-25\% y 37.5-50\%, PLL fue 8.09 y $6.56 \%$ mayor y con DL fue 41.72 y 33.68 días mayor, respectivamente. En conclusión, el genotipo con $62.5-75 \%$ de genes BT presentó el mejor comportamiento productivo; sin embargo, el comportamiento reproductivo fue similar en los genotipos estudiados.
\end{abstract}

PALABRAS CLAVE: Bovinos de doble propósito, Genotipos, Producción de leche, Duración de la lactancia.

\begin{abstract}
An evaluation was done of productive and reproductive performance in Bos taurus (BT) $x$ Bos indicus (BI) cattle in a dualpurpose system under tropical conditions in the state of Tabasco, Mexico. Records were from the UACH-URUSSE production unit, Teapa, Tabasco, and covered the years 1994 to 2011. Data included 492 births and 240 complete lactations of 130 Zebu or BT x BI

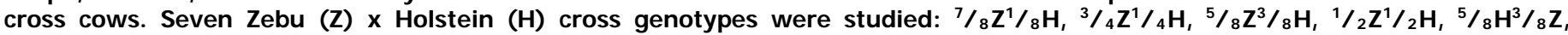
${ }_{11} /{ }_{16} \mathrm{H}^{5} /{ }_{16} \mathrm{Z}$ and $3 /{ }_{4} \mathrm{H}^{1} /{ }_{4} \mathrm{Z}$. Based on $\mathrm{BT}$ gene proportion, these genotypes were grouped into three categories: $0-25 \%$, 37.5-50\% and 62.5-75\% . Four variables were analyzed: birth weight (BW); interval between births (I BB); milk production per lactation (MPL); and length of lactation period (LLP). A higher proportion of BT genes was found to positively influence MPL $(P<0.05)$ and LLP $(P<0.01)$, but did not affect BW or IBB $(P>0.05)$. The $62.5-75 \%$ category had the highest MPL $(1,262.80 \pm 34.80 \mathrm{~kg})$, which was $8.09 \%$ higher than the $0-25 \%$ category and $6.56 \%$ higher than the $37.5-50 \%$ category. The $62.5-75 \%$ category also had the longest LLP (260.34 \pm 11.20 d), which was $41.72 \%$ longer than the $0-25 \%$ category and $33.68 \%$ longer the $37.5-50 \%$ category. Of the three categories, the $62.5-75 \%$ category exhibited the best production performance, although reproductive performance did not differ between the studied genotype categories.
\end{abstract}

KEY WORDS: Dual-purpose cattle, Genotypes, Milk production, Lactation period.

Recibido el 6 de febrero de 2015. Aceptado el 30 de marzo de 2015.

a Colegio de Postgraduados, Campus Tabasco. Periférico Carlos A. Molina, Km 3.5. Carretera Cárdenas-Huimanguillo. 86500 H. Cárdenas, Tabasco, México.

b Universidad Autónoma Chapingo, Unidad Regional Sur-Sureste (URUSSE). México.

c Colegio de Postgraduados, Campus Veracruz, Carr. Veracruz-Xalapa, rancho Tepetates. México.

d Universidad Popular de la Chontalpa. México.

* Autor de correspondencia: earanda@colpos.mx. 
La ganadería de doble propósito (DP) se desarrolla principalmente en la costa del Golfo de México que comprende el $28.3 \%$ del territorio nacional y concentra más del $40 \%$ del inventario bovino(1). En Veracruz, Chiapas y Tabasco se concentra el $80 \%$ de la ganadería de DP y el resto se distribuye en los diferentes estados con clima subtropical $^{(2)}$. Este sistema genera el $19.5 \%$ de la producción nacional de leche y el $50 \%$ de la producción de carne ${ }^{(3)}$.

El sistema DP es considerado como un sistema ganadero tradicional de producción en la región tropical, donde mediante cruzamientos de razas Bos taurus (BT) europeas especializadas o criollas con las razas Bos indicus (BI), se obtienen simultáneamente los productos leche y carne ${ }^{(1,4,5)}$. La finalidad del cruzamiento de estas dos especies es incrementar el potencial productivo mediante la inclusión de genes BT, mientras que los genes BI darán al nuevo genotipo la adaptación a las condiciones tropicales. El propósito de los productores ganaderos es incrementar los parámetros productivos y reproductivos al utilizar genotipos con alto grado de encaste, teniendo en cuenta que estos genotipos tienen mayores requerimientos (nutrición, sanidad, manejo, etc.) comparado con las razas $\mathrm{BI}$. Su principal característica es la práctica de un ordeño manual utilizándose el ternero para estimular la bajada de la leche ("apoyo"), criándolo hasta el destete, que coincide con la terminación de la lactancia ${ }^{(6,7)}$.

En el estado de Tabasco, la eficiencia reproductiva de las vacas se caracteriza por intervalos entre partos prolongados, bajos promedios de producción de leche por lactancia y periodos cortos de duración de la lactancia, especialmente en las vacas de doble propósito ${ }^{(6,8)}$. Por otro lado el peso al nacer es un parámetro productivo importante pues es la primera medida que se toma del animal después del nacimiento.

Conocer los parámetros del hato ganadero es de vital importancia, ya que son indicadores que señalan si los animales están expresando su potencial productivo y reproductivo. De no lograrse, el productor deberá de llevar acabo estrategias específicas en alimentación, manejo de los animales y potreros, sanidad, etc.
Con base en lo anterior, el objetivo del presente trabajo fue evaluar el efecto de los factores genotipo, año y época de parto, número de parto, sexo de la cría y el efecto del individuo sobre las variables peso al nacimiento (PN), intervalo entre partos (IEP), producción de leche por lactancia (PLL) y duración de la lactancia (DL) de vacas de doble propósito con distinto porcentaje de genes BT en el trópico húmedo.

La información se obtuvo de datos registrados entre 1994 y 2011, con 492 partos y 240 lactancias completas que correspondieron a los años 2003 a 2010 (en el periodo 1994-2002 no se tomaron los registros de producción de leche) de 130 vacas, de la unidad de producción de doble propósito de la Unidad Regional Universitaria Sur SuresteUniversidad Autónoma Chapingo, en Teapa, Tabasco. El municipio de Teapa se localiza en la región de la sierra a $17^{\circ} 32^{\prime} \mathrm{N}$ y $92^{\circ} 57^{\prime} \mathrm{O}$ con clima cálido húmedo, y lluvias todo el año; temperatura media anual de $27.8{ }^{\circ} \mathrm{C}$, y precipitación de 3,862.6 $\mathrm{mm}$ anuales ${ }^{(9)}$. La unidad presenta laderas con ligeras pendientes.

La información consistió en la identificación de la vaca, genotipo de la vaca, fechas de parto, número de parto, sexo de la cría, días de lactancia y producción de leche por lactancia.

El manejo consistió en el ordeño mecánico por la mañana (0005-0008 h); para lograr la bajada de leche se utilizó oxitocina en dosis de $2 \mathrm{ml}$ por vaca. En la ordeña se suministraba a los animales $250 \mathrm{~g}$ de melaza-urea, $90 \mathrm{~g}$ de sal mineral por día. Las vacas después de ser ordeñadas y de amamantar a sus crías (leche residual) durante 60 min, se llevaban a potreros con superficie de una hectárea de pasto señal (Brachiaria decumbens), estrella (Cynodon nlemfuensis), mulato (Brachiaria hibrido cv. mulato) y pastos nativos ( Paspalum sp.). Se realizaba un manejo rotacional de potreros con 2 días de ocupación y 30 días de descanso.

El manejo reproductivo fue por monta directa. La vacunación fue anualmente por medio de bacterina triple para septicemia hemorrágica, carbón sintomático y edema maligno. En las vacas en producción se llevó un control de mastitis por medio de la prueba de california que se realizaba cada 30 
días, las vacas que daban positivo a la prueba se eliminaban de la ordeña para ser tratadas.

El número de registros de las variables peso al nacer (PN), intervalo entre partos (IEP), producción de leche por lactancia (PLL) y duración de la lactancia (DL) fue de 476, 471, 240 y 240 , respectivamente. El número de vacas representadas en cada caso fue de 127 para PN e IEP, y 94 para PLL y DL. Los genotipos se agruparon considerando el porcentaje de genes BT, ya que la cantidad de información para cada genotipo era reducida, por lo que se formaron tres categorías (Cuadro 1 ).

En el factor año de parto la información del periodo 1995-1999 se redujo, por lo que se agruparon en uno solo, formando el año 1999, los demás años $(2000, \ldots, 2011)$ formaron cada uno una categoría individual. Los partos se agruparon por época de secas (febrero-mayo), lluvias (junioseptiembre) y nortes (octubre-enero).

Para el estudio de cada variable se consideró un modelo mixto utilizando el PROC MIXED de SAS ${ }^{(10)}$. Los modelos se determinaron de acuerdo a los objetivos del trabajo y atendiendo al número de observaciones para cada subclase de los factores considerados; de esta manera se obtuvieron los siguientes modelos:

Modelo para PN:

$$
\begin{aligned}
Y_{i j k l m n}=M+ & G_{i}+A_{j}+E_{k}+N_{l}+S_{m}+V_{n}\left(G_{i}\right) \\
& +\varepsilon_{i j k l m n}
\end{aligned}
$$

Donde: $Y_{i j k m n}=\mathrm{PN}, \quad M=$ media general de la población en estudio, $G=$ efecto fijo del i-ésimo genotipo, $A_{j}=$ efecto fijo del j-ésimo año de parto, $E_{k}=$ efecto fijo de la k-ésima época de parto, $N_{/}=$ efecto fijo del l-ésimo número de parto, $S_{m}=$ efecto fijo del m-ésimo sexo de la cría, $V_{n}\left(G_{i}\right)=$ efecto aleatorio del $n$-ésimo individuo anidado en el i-ésimo genotipo, y $\varepsilon_{i j k m n}=$ error aleatorio asociado con la $Y_{i j k / m n}$.

Modelo para intervalo entre partos (IEP) y DL:

$$
\begin{aligned}
Y_{i j k l m}=M+ & G_{i}+A_{j}+E_{k}+N_{l}+V_{m}\left(G_{i}\right) \\
& +\varepsilon_{i j k l m}
\end{aligned}
$$

Donde: $Y_{i j k m}=I E P \circ D L, M=$ media general de la población en estudio, $G=$ efecto fijo del i-ésimo genotipo, $A_{j}=$ efecto fijo del j-ésimo año de parto, $E_{k}=$ efecto fijo de la k-ésima época de parto, $N_{l}=$ efecto fijo del I-ésimo número de parto, $\mathrm{V}_{\mathrm{m}}\left(G_{i}\right)=$ efecto aleatorio del $\mathrm{m}$-ésimo individuo anidado en el i-ésimo genotipo, y $\varepsilon_{i j k / m}=$ error aleatorio asociado con la $Y_{i j k l m}$.

Modelo para PLL:

$$
\begin{aligned}
Y_{i j k l m n o}=M & +G_{i}+A_{j}+E_{k}+N_{l}+S_{m}+L_{n} \\
& +V_{o}\left(G_{i}\right)+\varepsilon_{i j k l m n o}
\end{aligned}
$$

Donde: $Y_{i j k m n o}=\mathrm{PLL}, \quad M=$ media general de la población en estudio, $G=$ efecto fijo del i-ésimo genotipo, $A_{j}=$ efecto fijo del j-ésimo año de parto, $E_{k}=$ efecto fijo de la k-ésima época de parto, $N_{l}=$ efecto fijo del l-ésimo número de parto, $\mathrm{S}_{\mathrm{m}}=$ efecto fijo del m-ésimo sexo de la cría, $L_{n}=$ efecto de la duración de la lactancia del individuo, $\mathrm{V}_{0}\left(G_{i}\right)=$ efecto aleatorio del o-ésimo individuo anidado en el i-ésimo genotipo, $\varepsilon_{i j k / m n o}=$ error aleatorio asociado con $Y_{i j k l m n o}$.

Las medias de cuadrados mínimos para las variables de respuesta analizadas se obtuvieron con la opción LSMEANS del paquete estadístico SAS ${ }^{(10)}$ y para la comparación de las medias se utilizó la opción "pdiff" del mismo paquete estadístico. Se establecieron en el modelo todas las interacciones que fueron posibles debido al número de observaciones, tales como $G^{*} E, A^{*} E$, sin embargo, se removieron, ya que no fueron significativas $(P>0.05)$. La interacción $G^{*} A$ a pesar que era de interés, no fue incluida en el modelo debido a que

Cuadro 1. Clasificación de los genotipos acorde al porcentaje de genes Bos taurus

\begin{tabular}{lccc}
\hline $\begin{array}{l}\text { Porcentaje de } \\
\text { genes Bos } \\
\text { taurus }\end{array}$ & Genotipos & $\begin{array}{c}\text { Número de } \\
\text { datos por } \\
\text { genotipo }\end{array}$ & $\begin{array}{c}\text { Datos por } \\
\text { clasificación }\end{array}$ \\
\hline $0-25$ & Cebú & 5 & \\
& $7 / 8 \mathrm{C}^{1} / 8 \mathrm{H}$ & 36 & 142 \\
$3 / 4 \mathrm{C}^{1} / 4 \mathrm{H}$ & 101 & \\
$37.5-50.0$ & $5 / 8 \mathrm{C}^{3} / 8 \mathrm{H}$ & 81 & 216 \\
& $1 / 2 \mathrm{C}^{1 / 2 \mathrm{H}}$ & 135 & \\
& $5 / 8 \mathrm{H}^{3} / 8 \mathrm{C}$ & 105 & \\
$62.5-75.0$ & $11 / 16 \mathrm{H}^{5} / 16 \mathrm{C}$ & 1 & 134 \\
& $3 / 4 \mathrm{H}^{1} / 4 \mathrm{C}$ & 28 & \\
\hline
\end{tabular}


Cuadro 2. Peso al nacimiento (PN), intervalo entre partos (IEP), producción de leche por lactancia (PLL) y duración de la lactancia (DL) de un hato de doble propósito en Tabasco, México

\begin{tabular}{lcrrrrrr}
\hline Variable & $\mathrm{n}$ & Media & \multicolumn{1}{c}{ DE } & \multicolumn{1}{c}{ EE } & CV & \multicolumn{1}{c}{ MIN } & \multicolumn{1}{c}{ MAX } \\
\hline PN, kg & 476 & 31.66 & 5.15 & 0.23 & 16.28 & 20.00 & 55.00 \\
IEP, días & 471 & 447.27 & 56.82 & 2.60 & 12.70 & 319.00 & 650.00 \\
PLL, L & 240 & 1148.19 & 560.56 & 36.03 & 48.82 & 179.55 & 3009.22 \\
DL, días & 240 & 237.23 & 96.74 & 6.30 & 40.77 & 72.00 & 561.00 \\
\hline
\end{tabular}

$\mathrm{DE}=$ desviación estándar; $\mathrm{EE}=$ error estándar; $\mathrm{CV}=$ coeficiente de variación; $\mathrm{MIN}=$ mínimo; $\mathrm{MAX}=$ máximo.

todos los genotipos no estaban representados en todos los años.

La media, desviación estándar, error estándar, coeficiente de variación, mínimos y máximos de las variables se aprecian en el Cuadro 2. El nivel de significancia de los efectos principales de las características productivas y reproductivas se presenta en el Cuadro 3, las medias de cuadrados mínimos de PN, IEP, PLL y DL se presentan en el Cuadro 4.

El promedio del PN $(31.66 \mathrm{~kg})$ obtenido, es similar a lo indicado por diferentes autores ${ }^{(11,12,13)}$ para razas puras y cruzas BT $x \mathrm{Bl}$.

En el año de parto se observó una gran variación entre los pesos al nacimiento $(P<0.01)$, el menor promedio de peso al nacer se observó en el año 2010 ( $28.94 \pm 0.73 \mathrm{~kg}$ ), mientras que los pesos máximos se registraron en los años 2002 y 2007 con pesos promedio de $34.72 \pm 1.16$ y $34.41 \pm 0.74 \mathrm{~kg}$, respectivamente (Cuadro 4). Los resultados se explican posiblemente debido a las diferentes

Cuadro 3. Nivel de significancia de los efectos principales sobre los parámetros en estudio

\begin{tabular}{lcccc}
\hline & \multicolumn{4}{c}{ Variables de respuesta } \\
Efecto & PN & IEP & PLL & DL \\
\hline Genotipo & 0.16 & 0.72 & 0.03 & 0.0053 \\
Año de parto & $<0.0001$ & $<0.0001$ & $<0.0001$ & $<0.0001$ \\
Época de parto & 0.14 & 0.0004 & 0.26 & 0.63 \\
Número de parto & 0.15 & $<0.0001$ & $<0.0001$ & 0.79 \\
Sexo de la cría & 0.0002 & - & 0.66 & - \\
\hline
\end{tabular}

$\mathrm{PN}=$ peso al nacimiento; $\mathrm{IEP}=$ intervalo entre partos; $\mathrm{PLL}=$ producción de leche por lactancia; $\mathrm{DL}=$ duración de la lactancia. condiciones ambientales que prevalecieron en cada uno de los años, lo cual repercutió en la alimentación de las vacas y en el desarrollo del feto, lo que dio como resultado las diferencias en peso entre años. Este resultado concuerda con otros estudios realizados en regiones tropicales, donde observaron la influencia del año de parto sobre el PN(14,15,16).

El sexo de la cría afectó el PN $(P<0.01)$; los machos fueron más pesados $(32.54 \pm 0.53 \mathrm{~kg}$ ) que las hembras en $1.66 \mathrm{~kg}$ (Cuadro 4). El mayor peso de los machos al nacimiento es debido a la alta tasa metabólica provocada por la acción precoz de la hormona testosterona a nivel fetall ${ }^{(17)}$. Este resultado ya se ha indicado ampliamente en otros estudios $^{(15,18,19)}$.

Las crías con genotipo 0-25\% BT, mostraron mayor peso al nacer que las crías de los otros genotipos; sin embargo, esta diferencia sólo fue numérica y no fue significativa ( $P>0.05)$. Los resultados coinciden con otros autores ${ }^{(20,21)}$ quienes reportaron un efecto no significativo del efecto del genotipo sobre el peso al nacimiento.

La época de parto no tuvo efecto sobre el PN $(P>0.05)$, resultados confirmatorios obtuvieron otros investigadores ${ }^{(14,18,19)}$, quienes lo atribuyeron a que la disponibilidad y calidad del forraje que consumieron las hembras durante la gestación en las épocas señaladas no permitió expresar alguna diferencia en el PN.

El número de parto no afectó el peso de las crías $(P>0.05)$; efecto similar se ha indicado para la raza Brahman $^{(19)}$. Estos autores atribuyen este resultado a la adaptación de los animales a las condiciones ambientales climatológicas, y a que no hubo variación en las condiciones de manejo de las 
hembras gestantes, manejo de potreros y disponibilidad de forraje. Una situación similar pudo haber ocurrido en este estudio.
La media general obtenida para el IEP fue de 447.27 días, superior a la encontrada por otros autores quienes obtuvieron una media de $427^{(7)}$ y

Cuadro 4. Medias de cuadrados mínimos ( \pm error estándar) para las variables estudiadas

\begin{tabular}{|c|c|c|c|c|c|c|c|c|}
\hline Factor & $n$ & PN (kg) & $n$ & IEP (días) & $\mathrm{n}$ & PLL (kg) & $n$ & DL (días) \\
\hline \multicolumn{9}{|l|}{ Genotipo: } \\
\hline $0-25 \%$ & 137 & $32.45 \pm 0.72^{\mathrm{a}}$ & 137 & $466.24 \pm 08.68^{a}$ & 86 & $1160.71 \pm 34.52^{b}$ & 86 & $218.71 \pm 10.72^{b}$ \\
\hline $37.5-50 \%$ & 210 & $30.96 \pm 0.54^{a}$ & 208 & $460.59 \pm 06.85^{a}$ & 93 & $1179.76 \pm 27.96^{b}$ & 93 & $226.42 \pm 08.88^{b}$ \\
\hline $62.25-75 \%$ & 129 & $31.72 \pm 0.70^{a}$ & 126 & $459.45 \pm 08.53^{a}$ & 61 & $1262.77 \pm 34.83^{a}$ & 61 & $260.34 \pm 11.20 \mathrm{a}$ \\
\hline \multicolumn{9}{|l|}{ Año de parto: } \\
\hline 1999 & 17 & $31.98 \pm 1.43$ ab & 15 & $460.15 \pm 14.74 \mathrm{ab}$ & - & - & - & - \\
\hline 2000 & 17 & $29.80 \pm 1.29 \mathrm{~b}$ & 17 & $461.44 \pm 12.74 \mathrm{ab}$ & - & - & - & - \\
\hline 2001 & 21 & $32.87 \pm 1.21 \mathrm{ab}$ & 20 & $482.26 \pm 11.89 a$ & - & - & - & - \\
\hline 2002 & 26 & $34.72 \pm 1.16$ a & 26 & $465.45 \pm 10.59 \mathrm{ab}$ & - & - & - & - \\
\hline 2003 & 26 & $32.13 \pm 1.38$ ab & 25 & $479.53 \pm 09.95^{a}$ & 9 & $1166.54 \pm 67.34$ bc & 9 & $211.15 \pm 26.58 \mathrm{bc}$ \\
\hline 2004 & 47 & $32.43 \pm 0.93 \mathrm{ab}$ & 47 & $464.19 \pm 08.07 \mathrm{ab}$ & 44 & $1175.84 \pm 36.39 \mathrm{bc}$ & 44 & $238.30 \pm 13.23 b$ \\
\hline 2005 & 42 & $31.88 \pm 1.01 \mathrm{ab}$ & 42 & $462.56 \pm 07.79 \mathrm{ab}$ & 40 & $1249.18 \pm 37.12 \mathrm{ab}$ & 40 & $264.57 \pm 13.68 \mathrm{ab}$ \\
\hline 2006 & 35 & $30.96 \pm 1.09 \mathrm{ab}$ & 35 & $454.33 \pm 07.75 \mathrm{ab}$ & 25 & $1373.65 \pm 41.62 \mathrm{a}$ & 25 & $307.50 \pm 16.29 \mathrm{a}$ \\
\hline 2007 & 41 & $34.41 \pm 0.74$ a & 41 & $447.06 \pm 07.02 \mathrm{ab}$ & 23 & $1307.92 \pm 41.36 \mathrm{ab}$ & 23 & $298.39 \pm 16.49 a b$ \\
\hline 2008 & 59 & $29.96 \pm 0.63 \mathrm{~b}$ & 58 & $431.63 \pm 06.09 \mathrm{~b}$ & 34 & $1000.58 \pm 34.87^{c}$ & 34 & $277.47 \pm 13.76$ ab \\
\hline 2009 & 40 & $29.47 \pm 0.81$ b & 40 & $445.21 \pm 06.83 \mathrm{ab}$ & 28 & $1140.84 \pm 43.48 \mathrm{bc}$ & 28 & $111.70 \pm 15.60 \mathrm{~d}$ \\
\hline 2010 & 55 & $28.94 \pm 0.73 \mathrm{~b}$ & 55 & $474.19 \pm 06.23^{a}$ & 37 & $1194.11 \pm 37.26$ ab & 37 & $172.16 \pm 14.42 \mathrm{~cd}$ \\
\hline 2011 & 50 & $32.72 \pm 0.74 \mathrm{ab}$ & 50 & $479.21 \pm 06.48^{a}$ & - & - & - & - \\
\hline \multicolumn{9}{|c|}{ Época de parto: } \\
\hline Seca & 112 & $31.56 \pm 0.70$ a & 113 & $450.25 \pm 07.01 \mathrm{a}$ & 59 & $1227.15 \pm 30.94 \mathrm{a}$ & 59 & $227.57 \pm 11.43 \mathrm{a}$ \\
\hline Lluvias & 223 & $31.21 \pm 0.54$ a & 220 & $466.89 \pm 06.33^{b}$ & 105 & $1203.85 \pm 26.18^{a}$ & 105 & $236.77 \pm 09.35^{a}$ \\
\hline Nortes & 141 & $32.37 \pm 0.61^{a}$ & 138 & $469.14 \pm 06.71^{b}$ & 76 & $1172.25 \pm 29.64^{a}$ & 76 & $241.13 \pm 10.76$ \\
\hline \multicolumn{9}{|c|}{ Número de parto: } \\
\hline 1 & 124 & $31.32 \pm 0.49$ a & 119 & $413.74 \pm 04.68^{c}$ & 53 & $1053.43 \pm 29.08^{c}$ & 53 & $239.54 \pm 11.76$ \\
\hline 2 & 89 & $32.37 \pm 0.53^{a}$ & 89 & $433.96 \pm 05.17$ bc & 45 & $1101.38 \pm 30.34 \mathrm{bc}$ & 45 & $238.09 \pm 12.25 \mathrm{a}$ \\
\hline 3 & 67 & $32.91 \pm 0.63^{\mathrm{a}}$ & 67 & $440.02 \pm 05.93^{b}$ & 30 & $1149.20 \pm 36.60 \mathrm{bc}$ & 30 & $251.72 \pm 14.78$ \\
\hline 4 & 49 & $32.96 \pm 0.73^{a}$ & 48 & $460.72 \pm 06.91 \mathrm{ab}$ & 25 & $1197.38 \pm 38.01 \mathrm{abc}$ & 25 & $245.26 \pm 15.48 \mathrm{a}$ \\
\hline 5 & 47 & $32.35 \pm 0.78$ a & 47 & $473.95 \pm 07.74^{a}$ & 32 & $1256.30 \pm 34.56 \mathrm{ab}$ & 32 & $229.98 \pm 13.95{ }^{a}$ \\
\hline 6 & 37 & $31.91 \pm 0.89$ a & 38 & $475.53 \pm 08.80^{a}$ & 25 & $1267.03 \pm 40.77 \mathrm{ab}$ & 25 & $252.88 \pm 16.31 \mathrm{a}$ \\
\hline 7 & 28 & $30.51 \pm 1.02$ a & 28 & $486.98 \pm 09.96^{a}$ & 15 & $1235.49 \pm 50.80 \mathrm{ab}$ & 15 & $221.73 \pm 19.61 \mathrm{a}$ \\
\hline 8 & 20 & $30.82 \pm 1.17$ a & 20 & $467.83 \pm 11.44 \mathrm{ab}$ & 8 & $1370.61 \pm 69.45^{\mathrm{a}}$ & 8 & $235.53 \pm 28.20^{a}$ \\
\hline 9 & 15 & $30.26 \pm 1.44$ a & 15 & $506.10 \pm 13.69$ a & 7 & $1178.91 \pm 84.18$ abc & 7 & $201.68 \pm 30.52 \mathrm{a}$ \\
\hline \multicolumn{9}{|l|}{ Sexo: } \\
\hline Hembra & 218 & $30.88 \pm 0.54 \mathrm{~b}$ & - & - & 117 & $1195.73 \pm 25.04 \mathrm{a}$ & - & - \\
\hline Macho & 258 & $32.54 \pm 0.53$ a & - & - & 123 & $1206.43 \pm 25.20 \mathrm{a}$ & - & - \\
\hline
\end{tabular}

abcdMedias con la misma letra en cada columna en una variable, son significativamente iguales (Tukey 0.05 ). 
432.9(22) días respectivamente para la cruza BT $\times$ BI . También fue superior a lo indicado para la raza Holstein en condiciones tropicales, con una media de 412.06 días $^{(23)}$; y fue inferior al reportado por otros autores quienes encontraron un promedio de $463^{(24)}$, $473.9^{(25)}, 469.2^{(26)}$ días. Este IEP es mayor al óptimo de 12 a 13 meses, sin embargo, es un valor común para condiciones tropicales, en donde la cría pasa con la madre un periodo muy amplio, y el amamantamiento alarga el periodo de anestro postparto y los IEP(7), debido al efecto inhibitorio que ejerce el amamantamiento sobre la actividad ovárica ${ }^{(27)}$.

El año de parto tuvo un efecto significativo sobre el IEP $(P<0.01)$, el cual mostró altibajos con el transcurso del tiempo (Cuadro 4). Este es un factor difícil de explicar ${ }^{(7,24)}$ debido a que incluye la variación de componentes ambientales, de manejo y la interacción de estos, que varían de año en año. Numerosas investigaciones, señalan la influencia que tiene el año de parto sobre el $\operatorname{IEP}(7,22,25,28)$.

La época de parto tuvo un efecto significativo sobre el IEP ( $P<0.01)$, el IEP más bajo se obtuvo en la época seca (450.25 días), y fue más prolongada en la época de nortes (Cuadro 4). Bajo las condiciones ambientales de Tabasco lo anterior pudiera explicarse debido a que en la época seca el suelo tiene humedad residual, lo que conlleva a la abundancia de pastos ${ }^{(29)}$, no así para la época de norte donde hay un lento desarrollo de los pastos ocasionado por el foto-período corto(30). Este efecto de la época de parto es similar a los reportados en otros estudios ${ }^{(7,22,28,31)}$.

El número de parto afectó el IEP $(P<0.01)$, con un incremento gradual conforme transcurrió el tiempo (Cuadro 4). El IEP tuvo un incremento de 92 días al pasar de 413.74 días en vacas de primer parto a 506.10 días en las vacas con nueve o más partos, aunque del cuarto al noveno parto las diferencias entre ellas no fueron significativas. Los resultados pudieran explicarse debido a que los animales de reemplazo tienen un buen manejo nutricional, lo que les da un desarrollo corporal completo y madurez sexual antes de iniciar su vida reproductiva. Los resultados de este trabajo concuerdan con los de varios investigadores $(7,22,25,28)$ quienes observaron que el número de parto es una fuente de variación importante para el IEP.

El genotipo no tuvo un efecto significativo sobre el intervalo entre partos $(P>0.05)$. La diferencia entre la media menor y mayor fue de tan solo seis días aproximadamente; un efecto similar del genotipo sobre la IEP en animales cruzados se ha reportado en otros estudios ${ }^{(7,32)}$, y difiere de otros investigadores $^{(22,28,33)}$, que observaron en el genotipo una fuente de variación sobre el IEP en animales cruzados.

La producción de leche por lactancia fue de $1,148.19 \mathrm{~kg}$, en animales suplementados con melaza-urea y un ordeño al día. Esta producción es inferior a la producción de leche encontrada en animales cruzados BT $\times$ Bl en el estado de Yucatán, donde se informa una producción de 1,862 \pm 814 $\mathrm{kg}^{(7)}$ en animales con un ordeño y suplementados con $3 \mathrm{~kg}$ de alimento comercial (18\% PC). En Veracruz con animales cruzados, con un manejo de dos ordeños, en pastoreo con pastos mejorados y suplementados con $1 \mathrm{~kg}$ de alimento comercial (18\% PC, 1.65 Mcal EM) por cada $3 \mathrm{~kg}$ de leche producida se informó una producción de leche de $4,961 \pm 416 \mathrm{~kg}^{(33)}$. En este mismo estado con vacas cruzadas Simental-Pardo Suizo-Cebú en pastoreo rotacional, con un ordeño diario, suplementados con $2 \mathrm{~kg}$ de alimento concentrado (13\% PC) y ensilaje de maíz alcanzando producciones de leche de $1,765.68 \mathrm{~kg}^{(34)}$. En Brasil con animales cruzados Holstein-Gyr, manejados con dos ordeños, con una alimentación basada en pastos mejorados, más ensilaje de maíz y alimento concentrado, indicaron una producción de $2,865.17 \mathrm{~kg}^{(35)}$ de leche por lactancia. De igual manera fue inferior a lo indicado para Holstein puro en condiciones tropicales de Tabasco, manejados con dos ordeñas, en pastoreo rotacional y suplementados con melaza-urea, alcanzando una producción de 3,075.12 kg ${ }^{(23)}$. Puede notarse que la introducción de genes BT incrementa el volumen de producción; sin embargo se observa una gran variación en ésta, influenciada principalmente por el sistema de ordeño, genotipo, manejo sanitario, las características de la alimentación, calidad y manejo de praderas. 
Los resultados obtenidos en este estudio están en el límite inferior del rango del potencial lechero de vacas cruzadas BT x BI que es de 1,000 a 4,961 $\mathrm{kg}$ de leche por lactancia en el trópico mexicano ${ }^{(37,38)}$. Esta baja producción posiblemente se debe al manejo general que se realizaba en la unidad de producción, ya que los animales solo recibían melaza-urea como suplemento, y a que diariamente recorren distancias entre 500 a 1,000 m (pradera-sala de ordeño) en condiciones de ladera, por lo que la energía que consumen la utilizan para el mantenimiento y no así para la producción.

El genotipo tuvo un efecto significativo sobre la PLL $(P<0.05)$. El genotipo de $62.25-75 \%$ de genes BT presentó la mejor producción con 1,262.77 \pm $34.83 \mathrm{~kg}$ comparada con los otros genotipos (Cuadro 4). Dicha producción fue $8.08 \%$ mayor que la producción del genotipo 0-25\% y $6.57 \%$ mayor que la producción del genotipo 37.5-50\%. Estos resultados coinciden con otros autores quienes observaron en el genotipo una fuente de variación ${ }^{(33,35,36,39)}$ y la mayor PLL la expresaron los genotipos con $75 \%$ de genes $\mathrm{BT}^{(33,36)}$. Este resultado se explica por los efectos complementarios de los genes heredados de las razas parentales, los animales BT trasmiten a la progenie cruzada la habilidad para aprovechar mejor los nutrientes, mientras que los Bl trasmiten información de adaptación al ambiente tropical(40).

El año de parto tuvo un efecto altamente significativo sobre el PLL $(P<0.01)$. La producción tuvo altibajos en los años de estudio. Inició con $1,166.54 \pm 67.34 \mathrm{~kg}$ en 2003, la cual fue incrementándose hasta alcanzar su máxima producción en $2006(1,373.65 \pm 41.62 \mathrm{~kg})$. Posterior a ese año la PLL fue disminuyendo alcanzando la producción más baja en el año 2008 con 1,000.58 土 $34.87 \mathrm{~kg}$ (Cuadro 4). El año de parto es una fuente de variación difícil de explicar ${ }^{(7,24)}$, debido a que comprende factores de manejo, ambientales y sus interacciones, además, su efecto es de naturaleza aleatoria y poco predecible. Los resultados obtenidos en este estudio concuerdan con los publicados por diversos investigadores ${ }^{(7,36,39)}$ quienes encontraron que el año de parto es una fuente de variación para la PLL.
El número de parto tuvo un efecto significativo sobre el PLL $(P \leq 0.01)$, la producción de leche se incrementó conforme aumentaron los partos (Cuadro 4). En el primer parto se registró una producción de leche de 1,053.43 $\pm 29.08 \mathrm{~kg}$, mientras que en el octavo parto se registró la máxima producción de leche de 1,370.61 \pm 69.45 $\mathrm{kg}$, teniendo un incremento de $317.18 \mathrm{~kg}$. Después del octavo parto la tendencia de la producción fue a disminuir. El efecto del número de parto sobre la PLL en animales cruzados coincide con otros autores $^{(36,39,41)}$. Este efecto pudiera explicarse debido a que durante la vida productiva de las vacas, las condiciones de manejo y alimentación no fueron las adecuadas para mantener la producción de leche de manera uniforme.

La época de parto no fue una fuente de variación para la PLL $(P>0.05)$; estos resultados coinciden con los de otros autores ${ }^{(7,33,39)}$ quienes observaron que la época de parto no afecta la PLL en las condiciones que desarrollaron sus estudios.

El sexo de la cría no tuvo un efecto significativo sobre la PLL ( $P>0.05)$, probablemente por el tipo de manejo de rejeguería, ya que el becerro solo se amamanta de la leche residual.

La media general de duración de la lactancia fue de $237.23 \pm 6.30$ días, inferior a $255 \pm 80$ días, reportados en Yucatán ${ }^{(7)}$. En el estado de Veracruz trabajando con vacas cruzadas Simental, Pardo Suizo y Cebú en pastoreo rotacional con una ordeña diaria se obtuvo una DL de 266.92 días $^{(34)}$. En Brasil trabajando con animales cruzados Holstein-Gyr, manejados con dos ordeños diarios alcanzaron una DL 283.79 días ${ }^{(36)}$. Así mismo fue inferior a la DL indicada en Tabasco para la raza Holstein pura con una media de 326.62 días $^{(23)}$; y fue superior a los valores de 153 y 172 días en vacas Holstein-Cebú y Suizo-Cebú en Tabasco respectivamente ${ }^{(42)}$.

El genotipo tuvo un efecto altamente significativo sobre la DL ( $P \leq 0.01)$. El genotipo de $62.25-75 \%$ de genes BT presentó la lactancia más prolongada con $260.34 \pm 11.20$ días comparada con los otros genotipos 0-25 \% y 37.5-50\% (Cuadro 4); dicha diferencia fue de 41.63 y 33.92 días respectivamente más alta que los genotipos mencionados. Lo anterior puede explicarse por las características genéticas de alta producción de la 
raza Holstein incorporados en estos cruzamientos. Resultados confirmatorios que son señalados por otros autores ${ }^{(7,33,35)}$, los cuales encontraron que el genotipo tuvo un efecto significativo sobre la DL.

El año de parto tuvo un efecto significativo sobre DL ( $P \leq 0.01)$, la cual se fue incrementando con el tiempo, inició con 211.15 días en el 2003 hasta alcanzar los 307.50 días en el 2006, en los dos años siguientes la DL disminuyó, pero se mantuvieron por encima de los 275 días. En el año 2009 la DL sufrió una caída drástica al observarse un valor de 111.70 días, en el siguiente año incrementó a 172.16 días (Cuadro 4). Estas diferencias pudieran ser atribuidas a la variación en el manejo en general del hato, ya que estuvieron bajo un sistema de producción comercial, y está sujeto a cambios en el mercado y disponibilidad económica; por ejemplo, en el año 2009 hubo un cambio en el manejo del hato de producción y se dejó de ordeñar. Estos resultados concuerdan con otros autores ${ }^{(7,36,41)}$ quienes también encontraron que el año de parto mostró un efecto significativo sobre la DL.

La época de parto y el número de parto no fueron una fuente de variación significativa para la DL $(P>0.05)$, resultados similares a los reportados por varios investigadores $(7,33,34)$.

Se concluye que los genotipos con proporciones 62.5 y el $75 \%$ BT presentaron la mayor producción de leche por lactancia y duración de la lactancia en comparación con los otros genotipos; el peso al nacimiento e intervalos entre partos fueron similares entre las tres categorías de genotipos. Del primero al octavo parto se incrementa la producción de leche por lactancia y después del octavo parto disminuye. Del primero al cuarto parto aumentó el Intervalo entre partos. A partir del quinto los intervalos entre partos fueron similares.

\section{AGRADECIMIENTOS}

Al Consejo Nacional de Ciencia y Tecnología (CONACYT) por la beca otorgada para el estudio del posgrado Producción Agroalimentaria en el Trópico del Colegio de Postgraduados, Campus Tabasco. A la UACH-URUSSE, por el aporte de la información que se utilizó en dicha investigación. Al Dr. José
Alfonso Hinojosa Cuellar por el apoyo en el análisis estadístico de la información. A las líneas de investigación LPI2: Agroecosistemas sustentables y LPI5: Biotecnología microbiana vegetal y animal, del Colegio de Postgraduados, por el apoyo otorgado.

\section{LITERATURA CITADA}

1. Pérez HP, Rojo R, Álvarez A, García J. Necesidades de investigación y transferencia de tecnología de la cadena de bovinos de doble propósito en el estado de Veracruz. Fundación Produce Veracruz. Veracruz, México; 2003.

2. Rivas L. El sistema ganadero de doble propósito en América Latina Tropical: evolución, perspectivas y oportunidades. Simposio Internacional sobre alternativas y estrategias en producción animal. Universidad Autónoma Chapingo, México. 1992.

3. Instituto Nacional de Estadística, Geografía, e Informática (INEGI). Censo Agropecuario 2007. www.inegi.gob.mx. Consultado 15 J un, 2014.

4. CONARGEN. Comité Nacional de los Recursos Genéticos. Plan de Acción. México, DF. 2000.

5. Castañeda O, Lagunes J, Castillo H, Ávila A. Utilización de sementales híbridos para el mejoramiento genético de la ganadería de doble propósito. Día del ganadero. Centro Experimental La Posta-CIR Golfo Centro-I NIFAP. Veracruz, México; 2001:19-33.

6. Osorio AMM. Producción bovina de doble propósito en el trópico “La Rejeguería": el mejoramiento genético de los animales. ISPROTAB, Colegio de Posgraduados. Villahermosa, Tabasco; 2000(3):52-55.

7. Hernández-Reyes E, Segura-Correa VM, Segura-Correa JC, OsorioArce MM. Intervalo entre partos, duración de la lactancia y producción de leche en un hato de doble propósito en Yucatán, México. Agrociencia 2001;35:699-705.

8. Instituto Nacional de Investigaciones Forestales, Agrícolas y Pecuarias (INIFAP). Manejo de ganado bovino de doble propósito en el trópico. Libro técnico No. 5. Veracruz, México. 2000.

9. García E. Modificaciones al sistema de clasificación climática de Köppen, para adaptarlos a las condiciones de la República Mexicana. Universidad Nacional Autónoma de México. México DF. 1973.

10. SAS ${ }^{2}$. SAS User's Guide: Statistics (version 9.4). Cary NC, USA. SAS Institute Inc. 2012.

11. Manrique PC. Conociendo la genética de la raza. El Cebú 2003; 305:48-50.

12. López BB, Esperón SAE, Martínez MS, Carmona MMA, Contreras. Efecto del año, mes, sexo de la cría y número de parto sobre el peso al nacimiento de cuatro razas cebuinas en el trópico húmedo [resumen]. Congreso Nacional de Buiatria. 2005:115.

13. Aranguren MJ, Román BR, Villasmil OY, Chirinos FZ, Romero J, Soto BE. Componentes de (co)varianza y parámetros genéticos para características de crecimiento en animales mestizos de doble propósito. Rev Cient, FCV-LUZ 2006;16(1):55-61.

14. Segura CJA. Comportamiento hasta el destete de un hato cebú comercial en el sureste de México. Livest Res Rural Develop 1990;2(1). 
15. Domínguez VJ, Núñez DR, Ruíz FA. 2003. Influencias ambientales e índice de constancia para características de crecimiento en ganado bovino Tropicarne. Téc Pecu Méx 2003;41(1):1-18.

16. Ossa GA, Suárez MA, Pérez JE. 2007. Efectos del medio y la herencia sobre los pesos al nacimiento, al destete y a los 16 meses de edad en terneros de la raza criolla Romosinuano. Revista Corpica-Ciencia y Tecnología Agropecuaria 2007;8(2):81-92.

17. Bracho I, Contreras GPM, Zambrano Z. La raza Criollo Limonero: Una realidad para la ganadería de doble propósito. CGS editores. Maracaibo, Venezuela: Ediciones Astro Data; 2002:11-39.

18. Medina ZJM, Osorio AMM, Segura C C. Influencias ambientales y parámetros genéticos para características de crecimiento en ganado Nelore en México. Rev Cient 2005; 15(3):235-241.

19. Montes VD, Vergara GO, Prieto ME, Rodríguez PA. Estimación de los parámetros genéticos para el peso al nacer y al destete en ganado bovino de la raza Brahman. Rev. MVZ Córdoba 2008; 13(1): 1184-1191.

20. Teyer R, Magaña JG, Santos J, Aguilar C. Comportamiento productivo y reproductivo de vacas de tres grupos genéticos en un hato de doble propósito en el sureste de México. Rev Cub Cienc Agr 2003;37(4):363-370.

21. Martínez GJ C, Azuara MA, Hernández MJ, Parra BGM, Castillo RSP. Características pre-destete de bovinos Simmental (Bos taurus) $\mathrm{x}$ Brahman (Bos indicus) en el trópico mexicano. Rev Colomb Cienc Pecu 2008;21:365-371.

22. Mejía-Bautista GT, Magaña JG, Segura-Correa JC, Delgado R, Estrada-León RJ. Comportamiento reproductivo y productivo de vacas Bos indicus, Bos taurus y sus cruces en un sistema de producción vaca: cría en Yucatán, México. Trop Subtrop Agroecosystems, 2010;12(2):289-301.

23. Martinez F, Queijeiro M, Guimond H, Scoffield J . Ganadería lechera en el trópico húmedo de México. Experiencia de una década en la Chontalpa. Nestlé. Cárdenas, Tabasco, México. 1986.

24. Osorio-Arce M, Segura-Correa J. Reproductive performance of dualpurpose cows in Yucatán, México. Livest Res Rural Develop 2002;14:1-9 http://www.cipav.org.co/Irrd//rrd14/3/ Osor143.htm. Consultada 7 Oct, 2014

25. Arellano CMS, Martínez GJ C, Romero TEM, Briones EF, Domínguez MM, De la Garza RF. Factores genético-ambientales que afectan el intervalo entre partos y días a primer parto en ganado de doble propósito en el norte de Veracruz. Rev Al A 2006; 10(1):43-53.

26. Vergara GO, Botero AL, Martínez BC. Factores ambientales que afectan la edad al primer parto y primer intervalo de partos en vacas del sistema doble propósito. Revista MVZ Córdoba 2009; 14(1): 1594-1601.

27. Segura CVM, Rodríguez ROL. Comportamiento reproductivo de vacas cebú sometidas a amamantamiento nocturno. Téc Pecu Méx 2000;38(1):67-72.

28. López OR, Díaz HM, García MJG, Nuñez DR, López OR, Martínez HPA. Eventos reproductivos de vacas con diferente porcentaje de genes Bos taurus en el trópico mexicano. Rev Mex Cienc Pecu 2010;1(4):325-336.
29. Meléndez NF. Manual de manejo de praderas para tabasco. Secretaria de Agricultura y Desarrollo Rural. Instituto Nacional de Investigaciones Forestales, Agrícolas y Pecuarias. Centro de Investigación Regional Golfo Centro. Campo Experimental Huimanguillo, Tabasco, México. Folleto técnico No. 22. 1998.

30. De las Heras TJ G, Osorio AMM, Segura CJ C; Aranda IE, Aguilar CJA. Factores que afectan las constantes de la curva de crecimiento de becerros en un sistema de doble propósito en el trópico. Rev Cient 2008; 18(4):393-397.

31. Magaña JG, Segura JC. Estimates of breed and heterosis effects for some reproductive traits of Zebu and Brown Swiss in southeastern Mexico. Livest Res Rural Develop 2001;13(5). http://www.Irrd.org/ Irrdl3/5/maga135.htm. Consultado 10 Feb, 2013.

32. Vergara GO, Salgado OR, Maza AL, Botero AL, Martínez BC, Medina GC, Pestana SJ. Factores que afectan el primer intervalo de parto de hembras bovinas manejadas bajo el sistema doble propósito. Livest Res Rural Develop 2007;19(10). http://www.Irrd.org/ Irrd19/10/verg19140.htm. Consultado 10 Ene, 2013.

33. López-Ordaz R, Vite-Cristóbal C, García-Muñiz JG, MartínezHernández PA. Reproducción y producción de leche de vacas con distinta proporción de genes Bos taurus. Arch Zoot 2009; 58(224):683-694.

34. Ríos UA, Hernández HVD, Amezcua MEV, Zárate MJP. Producción láctea de vacas simmental $\mathrm{x}$ cebú y suizo pardo $\mathrm{x}$ cebú en clima tropical. Agron Mesoam 2015;26(1):17-25.

35. Facó O, Lôbo RNB, Martins FR, Melo LFA. Idade ao Primeiro Parto e Intervalo de Partos de Cinco Grupos Genéticos Holandês x Gir no Brasil. Rev Brasileira Zoot 2005;34(6):1920-1926.

36. Mcmanus C, Teixeira AR, Talarico DL, Louvandini H, Bianchini OEM. Características productivas e reproductivas de vacas Holandesas e mesticas Holandes x Gir no Planalto Central. Rev Brasileira Zoot 2008;37(5):819-823.

37. González SC, Goicochea J, Rodríguez MA, Madrid-Bury N, González VD. Incorporación al servicio en novillas mestizas doble propósito. ALPA 2006; 14:1-9.

38. Lopez R, Thomas MG, Hallford DM, Kiesler DH, Silver GA, Obeidat BS, et al. Case study: Metabolic hormone profiles and evaluation of associations of metabolic hormones with body fat and reproductive characteristics of Angus, Brangus, and Brahman heifers. The Profesional Anim Scientist 2006;22:273-282.

39. López OR, García CR, García MJ G, Ramírez VR. 2009. Producción de leche de vacas con diferente porcentaje de genes Bos taurus en el trópico mexicano. Téc Pecu Méx 2009;47(4):435-448.

40. Madalena FE. La utilización sostenible de hembras F1 en la producción del ganado lechero tropical. Estudio FAO Producción y Sanidad Animal № 111. Rome, Italia; 1993.

41. Vite-Cristóbal C, López-Ordaz R, García-MuñizJG, Ramírez-Valverde R, Ruiz-Flores A, López-Ordaz R. Producción de leche y comportamiento reproductivo de vacas doble propósito que consumen forrajes tropicales y concentrados. Vet Méx 2007;38:63-79.

42. Silva LM, Granados ZL, Orozco LF. Producción láctea y comportamiento reproductivo de un hato de doble propósito en la sabana de Huimanguillo, Tabasco [resumen]. Reunión Nacional de Investigación Pecuaria. INI FAP. Chapingo, México; 1989:189. 